This is a post-refereeing final draft. When citing, please consult the following published version: http://dx.doi.org/10.1177/1468797611403040

Cohen, S.A. (2010). Chasing a myth? Searching for 'self' through lifestyle travel. Tourist Studies, 10(2), pp. 117-133.

\title{
Chasing a myth? Searching for 'self' through lifestyle travel
}

\author{
Scott A. Cohen
}

Bournemouth University, School of Tourism, UK

\begin{abstract}
This paper problematises the concept of searching for self in the context of lifestyle travellers - individuals for whom extended leisure travel is a preferred lifestyle that they return to repeatedly. Qualitative findings on the search for self from in-depth semi-structured interviews with lifestyle travellers in northern India and southern Thailand are considered in light of opposing academic perspectives on self. The study reveals a theoretical tension that exists between lifestyle travellers who may seek a unified sense of self, underpinned by the essentialist position that one's 'true self' exists, and contrasting widely held academic viewpoints that instead conceptualise embodied selves as relational and open to multiple performances.
\end{abstract}

\section{Keywords}

self, searching, lifestyle travellers, essentialism, social construction

\section{INTRODUCTION}

Searching for 'self' through travel has a lengthy tradition in popular literature (Goeldner \& Ritchie, 2006) that is also reflected in tourism scholarship. For instance, Richards and King (2003) suggest that some backpackers are travelling to 'find themselves', Cohen (1996) notes self-actualisation as a travel motive and Neumann (1992: 182) contends that 'journeys provide the opportunity to acquire experiences that become the basis for discovering and transforming one's self.' Searching for self, however, is by no means limited to the context of tourism. Baumeister (1986) and McAdams (1997) note that searching for self is pervasive in modern societies as many Western individuals seek an idea of self that reflects unity and purpose. 
Tourism may afford increased contact with an array of cultural praxes and ways of life that can challenge notions of self. Indeed, Davidson (2005: 31) observes that contemporary research on 'independent travellers' is largely united by a desire to understand how these individuals 'incorporate their travelling experiences into their own conception of selfidentity.' Although the importance of self to tourism studies has long been theorised (see Crompton, 1979), self is a contested concept within the social sciences. Seigel (2005) notes that 'few ideas are both as weighty and slippery as the notion of self', and as such it is no surprise that opposing theoretical perspectives on self are represented in the academic literature. Within tourism scholarship, however, the concept of self has frequently been essentialised (see for instance Cohen, 1996; Neumann, 1992; Richards \& King, 2003), which ignores the socially positioning power of discourse in the dialogical construction of selves (Appiah, 1994). Perhaps the literature in these cases has reflected the ambitions of certain tourists. As Rojek (1993: 178) suggests of the searching behaviour of some tourists - 'the traveller views travel experience as a resource in the quest for self-realization.'

In a departure from much previous tourism research that has employed the concept of self through a Romantic lens that reproduces essentialising concepts such as self-actualisation, self-realisation, self-fulfillment, discovering one's self and self-development, this paper problematises the concept of searching for self in the context of tourism. Opposing theoretical perspectives on self are reviewed, which includes first tracing and locating the historical status of an essentialist self. This highlights how the notion of a 'true inner self' is socially constructed and culturally contingent. In contrast, divergent understandings of selves as relational and performed, which are now widely accepted in the broader social sciences, are then discussed. Through these latter understandings, I illustrate how the ambitions of some tourists, who may seek a core or 'true inner self', can be viewed as the pursuit of an illusion. Empirical evidence to this end is based on in-depth semi-structured interviews with lifestyle travellers in northern India and southern Thailand in 2007, individuals for whom extended leisure travel is a preferred way of life.

\section{SEARCHING FOR 'SELF'}

Tourism studies have addressed the general theme of personhood as a tool in understanding tourism consumption, often using the terms self and identity interchangeably (Desforges, 2000). With the notable exception of Wearing and Wearing (2001), most tourism research on personhood employs identity as its orienting concept (Desforges, 2000). Whilst the permeability of self and identity as concepts allows them to sometimes merge into each other (Seigel, 2005) and they are described as co-terminus (Collinson \& Hockey, 2007), self can be distinguished from identity. The idea of self in its own right is historically a relatively new idea (Vaughan \& Hogg, 2002), as the word 'self' first appeared as a noun in the English language at the beginning of the $14^{\text {th }}$ century (Danziger, 1997).

Hall (1996) describes identities as temporary points of attachment to subject positions constructed through discursive practices. Identity is constructed through difference, as the recognition of what one is not in relation to the 'Other' (Hall, 1996; Walseth, 2006). Though distinctions have been drawn between collective and personal identities (Appiah, 1994), Breathnach (2006: 113) observes that identities are 'neither wholly collective nor individual, but are formed in the interaction between the individual and the subject positions available to them.' In contrast, Jenkins (1996: 29) defines self as 'each individual's reflexive sense 
[emphasis added] of her or his own particular identity, constituted vis à vis others in terms of similarity and difference.' Or as Gergen (1991: x) suggests, self refers to 'our ways of understanding who we are and what we are about.' Wearing and Wearing (2001) emphasise that self-understandings are housed in our physical body and include emotions, which furthers an understanding of self towards materially embodied subjective perceptions of 'I'.

Issues of self are widespread in modern Western societies, with Baumeister (1991: 6) noting from that 'the theme of self dominates recent trends in our culture.' The root of self as a point of concern is the often deeply ingrained essentialist view of 'human beings as selfcontained unitary individuals who carry their uniqueness deep inside themselves, like pearls hidden in their shells' waiting to be found (Burkitt, 1991: 1). This essentialist position suggests that each individual is born with the potential to develop an embedded singular personality that can be likened to the growth of a seed (Hughes, 1993). In order to understand how this concept of an essentialist self or 'true inner self' has become a widely-held narrative in modern Western imaginations, it is helpful to trace its historical status.

\section{An essential history}

The idea of the human as a unique individual was largely suppressed during the Middle Ages in medieval Europe as people tried to conform to the religious ideals set by a rigidly structured society wherein the primary determinants of identity at the time (lineage, gender, home and social class) were fixed by birth (Baumeister, 1986, 1991). Near the end of the Middle Ages, the Renaissance is credited with expanding on the notion of individuality as identity gradually became less determined by family descent (Simmel, 1971). In the $17^{\text {th }}$ century, John Locke's then controversial Essay Concerning Human Understanding posits that a human is born with her/his mind as a blank state, or tabula rasa, from which the self, as fixed in the material body, is henceforth based on a continuity of consciousness (Seigel, 2005). Locke sets a foundation for self as internal and objectifiable, thereby contributing to an essentialist understanding of the self over the next two centuries as a worldly phenomenon to be analysed and known (Danziger, 1997).

As individuals gradually became less content with religious versions of how life should be constructed, positive connotations of a private self reflected a growing desire to 'try out new models of human fulfillment', which would take place while the individual was living, rather than in an afterlife (Baumeister, 1986: 59; Vaughan \& Hogg, 2002). The secularised self assumed the form of a private 'object of variable worth' and the aspiration of increasing or maintaining its worth came 'to be regarded as an identifiable human motive' (Danziger, 1997: 145). Moreover, a growing tendency towards individualism ripened into subjects becoming more likely to describe themselves in terms of internal characteristics that might make them unique from others, such as personality traits, rather than in terms of their collective affiliations with other people (Ward, Bochner \& Furnham, 2001). The early modern period thus proffers the individual a foundation for conceptual separation from the social order (Baumeister, 1986), which develops into a strong sense of individualism in the Western consciousness during the Romantic era at the start of the late $18^{\text {th }}$ century (Simmel, 1971).

The Romantic era continues the idea that each individual contains an inner, natural self that is distinct from society (Leed, 1991). With a view of society as oppressive to the potential of the individual, Romantics place a high value on the ideal of freedom (Baumeister, 1986). Out of the notion that each person might exercise her/his potential to be unique, and 
that one's potential can best be achieved relatively independently of the social environment, grows the humanist modern view of an essentialist inner self that can be developed, fulfilled or actualised (Maslow, 1970, 1971; Rogers, 1969). With religion's meta-criteria for making decisions increasingly destabilised, Western individuals came to reflect upon their 'true inner self' as a moral source for direction in life's choices (Baumeister, 1986; McAdams, 1997). Although this meta-narrative of one's 'true self' as an inner source may still be pervasive in late modernity (McAdams, 1997), academic discourse now widely challenges the notion of an essentialist self.

\section{Social selves}

An essentialist understanding of self reflects a monological view, which fails to recognise selves as dialogically constructed through discourses made available by society (Appiah, 1994; Hall, 1996). In moving towards a dialogical conceptualisation of self in the early $20^{\text {th }}$ century, the sociologists Cooley and Mead set the stage for instead understanding self as a social phenomenon 'crafted through linguistic exchanges with others' (Ashmore \& Jussim, 1997; Harter, 1997: 81). This school of thought, termed 'symbolic interactionism', proposes that an individual's 'self-conception comes from seeing ourselves as others see us,' a concept known as 'the looking-glass self' (Vaughan \& Hogg, 2002: 84). Theory on the social self is further extended by Goffman's (1959) seminal work The Presentation of Self in Everyday Life, wherein he uses a theatrical context to conceptualise self as a dramaturgical performance in which actors perform different roles for different people.

Through symbolic interactionism and the dramaturgical metaphors of Goffman (1959), sociology brought to the fore of the discussion on self the idea that 'selves are constructed, modified and performed in interaction with other people' (Vaughan \& Hogg, 2002: 101). This suggests that rather than one fixed essentialist self, each individual has multiple selves that are contextually dependent. Perspectives that conceptualise self as relational, or situational (Finnegan, 1997), have gained speed with the help of discursive theory that is based on Foucauldian understandings of the self as linguistically constructed (Holland, 1997). Foucault (1988) deconstructs the essentialist self by situating it historically within linguistics. Through linguistic practice, or 'technologies of the self' (Foucault, 1988), individuals are institutionally encouraged to learn socially condoned procedures for systematically reflecting upon their own thoughts, feelings and behaviors. For instance, the common modern practice of keeping a personal diary, the Catholic practice of confession and the increase in modern popular literary productions that are preoccupied with the idea of an inner self can each be seen as influential technologies of the self (Danziger, 1997).

A Foucauldian discursive self is underpinned by observations that socially sanctioned technologies of the self may be instituted and understood in diverse ways across different cultures (Danziger, 1997). If self-introspection is understood as culturally contingent and constructed through text: "the "real self", the search for which is the very cornerstone of Romanticism, does not exist' (Beedie, 2007: 40). Without a true inner self, embodied self is reduced to a multitude of relational selves that are contextualised and permeable (Holland, 1997). This poststructural objection to an inner self is not intended as a nihilistic outlook, quite on the contrary, the idea is 'the more selves the merrier' (McAdams, 1997: 51). Thus, while discursive theory deconstructs the ideal of 'liberation' through self-knowledge (Cohen 
\& Taylor, 1992), it also theoretically paves the way for increasing possibilities (Gergen, 1991).

Even though a discursive understanding of selves lends considerable capital to sociological perspectives of selves as multiple and fluid, McAdams (1997: 47) warns that 'one should not dismiss the possibility that selves nonetheless retain a certain degree of unity and coherence.' Holland (1997: 171) notes that two poles with a continuum in between can be seen in contemporary academic discussions on self, with the range including 'an extreme essentialist view that pays no attention to the socially positioning power of discourse and an extreme ephemeralist position that has no interest in the embodied self.' With regards the latter 'ephemeral' Foucauldian view, also referred to as 'discourse determinism' (Wearing \& Wearing, 2001), criticism is launched at the idea that text has total power to 'set strict limits to what people are able to think, or deeming consciousness to be so fully constituted by social and cultural relations that mental life becomes a kind of precipitate of collective existence, losing its independence' (Seigel, 2005: 21). In counterargument, although Giddens (1991: 2) asserts that 'the self is not a passive entity,' to attribute the individual a Romanticised 'total freedom' from the power of discourse would be far overstating the case (Finnegan, 1997).

Butler's (1990) work on the performativity of gender offers a useful perspective on constructing selves that may help to bridge the gap between the power of discourse and embodied agents (Bell, 2008). In the context of constituting selves, Bell (2008: 174) observes that 'performativity has come to mean that we perform multiple and shifting identities in history, language, and material embodiments.' Butler notes that the constitution of selves is an embodied performance that is processual, wherein individuals are always 'on the stage' and 'within the terms of the performance' (1990: 277), yet 'just as a script may be enacted in various ways, and just as the play requires both text and interpretation' so can individuals 'expand the cultural field bodily through subversive performances of various kinds' (p.282). Thus, while all performances are citations, or enacted ways of doing, for instance, class, gender, ethnicity, age and abilities, selves are also performative in that they are negotiated in and through a process of becoming (Bell, 2008). Selves are not fixed givens, but are always in process and performed.

\section{Social saturation}

The search for a singular core self is not only problematic due to the socio-historic 'reification' of an illusory inner self (Baumeister, 1986), but also because selves in late modernity are set within a growing array of life options (Giddens, 1991). Contemporary selves are increasingly fragmented and fractured as they are 'multiply constructed across different, often intersecting and antagonistic, discourses, practices and positions' (Hall, 1996: 4). The late modern age in particular is marked by an 'opening' of social life in which some individuals have a higher level of choice over matters of personal meaning, with this latitude for self-definition also coinciding with new socialising technologies, such as the Internet, television, air travel, radio and telephone that have radically changed human relationships (Cote \& Levine, 2002; Gergen, 1991; Giddens, 1991). Local face-to-face interactions are rarer, while globalisation, which is marked by these new technologies, exposes individuals to a new range of persons, forms of relationships, options and opportunities for constructing and exploring selves (Gergen, 1991). As some aspects of identity have become more a matter of choice rather than social ascription, individuals are forced to negotiate relational selves among 
an increasing diversity of options that can be transitory, fragmented and unstable (Cote \& Levine, 2002; Giddens, 1991).

The impact of these new socialising technologies is that many late modern individuals are reaching a state described by Gergen (1991) as 'social saturation', which produces a considerable change in our ways of understanding ourselves. In tension with a modern or humanist view of an inner self as unified and actualisable, social saturation suggests a cacophony of relational selves - "for everything we "know to be true" about ourselves, other voices respond with doubt and even derision' (Gergen, 1991: 6). Despite fragmented contemporary selves, Gergen (1991: 157) notes that 'it would be foolish to propose that a consciousness of relational selves is widely shared in Western culture.' Albeit individuals may outwardly perform relational selves by offering various narratives across different situations, through the embodied notion of 'I', individuals do attempt to synthesise subjective experience into a reflective conception of self (McAdams, 1997). Indeed, instead of living a life fully 'dictated by communal consciousness', wherein one ceases to believe in the self as an autonomous agent, (Cote \& Levine, 2002: 28; Gergen, 1991), many individuals still seek to form 'a patterned collection of social practices that constitute a sense of continuity and stability'; in this context, the self becomes an 'anchoring' or sense-making device (Kuentzel, 2000: 87).

Although self continues to be a contested concept, it is clear that the myth of an essentialist true self has been largely dispelled in academic circles. Even though selves in late modernity may be widely accepted in the academic literature as relational, fluid and performed, a tension can still exist for modern individuals who seek to develop a coherent sense of self among an increasing array of life options. For individuals on the modern treadmill of self-development, who may try to actively construct a unified sense of self through narratives 'rooted in the human propensity to remember and project' (Seigel, 2005: 653), maintaining a coherent sense of self in the context of social saturation is inherently problematic. Indeed, as tourism can involve exposure to an array of cultural praxes as individuals encounter the Other, tourism, and in particular here, the enduring involvement characteristic of lifestyle travel, is a context where issues relating to searching for self may be especially important.

\section{The context of lifestyle travel}

Lifestyle is suggested as progressively more important in late modern social life as the breakdown of traditional roles, which previously contributed to a more secure sense of self, has made in turn, for some, lifestyle choice critical in the (re)constitution of self (Giddens, 1991). There exists a small proportion of individuals for whom extended leisure travel is not a moratorium or transition to another life stage, as is typically described of the majority of backpackers (Maoz, 2007; Sørensen, 2003), but instead constitutes an ongoing lifestyle choice. A number of studies focused on backpackers speculate that a small number of individuals, or 'travellers', as they prefer to self-identify themselves, instead of 'tourists' (O'Reilly, 2005; Welk, 2004), return to extended travel serially, and as such, treat travel as a way of life (see Cohen, 1979; Noy \& Cohen, 2005; Riley, 1988; Uriely, Yonay \& Simchai, 2002; Welk, 2004; Westerhausen, 2002).

Noy and Cohen (2005) hold that such 'lifelong wanderers' or 'contemporary drifters' (Cohen, 2004) are difficult to locate and have rarely been the subject of research. Individuals 
reflective of Cohen's (2004) contemporary drifters and Noy and Cohen's (2005) lifelong wanderers, who repeatedly and indefinitely return to extended leisure travel, are referred to here as 'lifestyle travellers' (see also Cohen, 2010a,b). Lifestyle traveller is a less pejorative term than 'drifter' or 'wanderer' to represent an individual who travels as a lifestyle choice (Cohen, 2011) and provides the context for this paper's findings on searching for self.

\section{Method}

The empirical material presented here is based on 25 in-depth semi-structured interviews with lifestyle travellers in northern India and southern Thailand from July through September 2007. My own six years of lifestyle travel experience prior to this research helped me in gaining access to the social world of lifestyle travellers. The inclusion criteria for participants was a fluid combination in which each interviewee self-defined travel as her/his lifestyle and had been on multiple backpacking trips of approximately six months or more. This latter criterion served as a temporal starting point, as in the end most of the participants had taken several trips in the broad range of six months to one year, with three having each travelled the longest at approximately 17 years.

Albeit lifestyle travellers are spread through many regions of the world, northern India and southern Thailand offered fieldwork sites with established gathering points for conveniently accessing lifestyle travellers. The selection of northern India and southern Thailand was based on my personal experiences of encountering a high number of lifestyle travellers in popular traveller gathering points in these countries on my previous trips, as well as literature that represents India and Thailand as attractive destinations for extended travel (Davidson, 2005; Richards \& Wilson, 2003; Westerhausen, 2002). Specifically, lifestyle travellers were accessed in the towns of Rishikesh, Manali, McLeod Ganj and Leh in northern India and on the islands of Koh Phangan and Koh Tao in southern Thailand.

Entering the field overtly as both a researcher and a 'traveller', I integrated with other travellers through dressing like them, socialising with them and moving through daily routines in the same networks of accommodation and eating facilities, a technique used by Davidson (2005), Riley (1988) and Sørensen (2003). Lifestyle travellers were identified through casual conversations with backpackers in which the introductory dialogues often turned to how long each person intended to travel. Through the course of many conversations, I periodically found I was speaking to a lifestyle traveller or was subsequently introduced to one. The interviews were digitally recorded and often took place in the same settings the participants had originally been encountered, frequently over a meal or drink. The interviews were largely conversational and focused on the tourism biographies of the participants, their reasons for travelling as a lifestyle and whether the meaning(s) they assigned to travel had changed over time.

The majority of the participants travelled alone and were from a range of 13 nationalities with English, Australians, Israelis and Canadians the most commonly represented. There were 11 females and education levels were spread from high school dropout to masters degree holder. Participant age ranged from 23 to 50, with an average age of 30. Following transcription, the empirical material was interpreted using a thematic analysis approach that consisted of searching for emergent themes (Patton, 2002; Veal, 2006). This approach involved reducing the empirical material into categories guided by the participants' narratives without losing sight of the research aims (Miles \& Huberman, 1994). 
From these themes were derived insights and subsequent interpretations as to the meanings the lifestyle travellers attributed to self in their travels (Patton, 2002).

\section{Approaches to self-searching}

A complex array of approaches to searching for self emerged that indicated that selfsearching played an important motivating factor for the majority of the lifestyle travellers. Furthermore, a thread that linked many of the lifestyle travellers together was the Romantic modern belief that each individual has an essentialist 'true inner self' that can be developed or actualised. In support of the importance of searching for self in lifestyle travel, Simon (Swiss, 50), the oldest of the participants, remarked 'I think everyone looks, searching for their self.' Another seasoned traveller, Ryan (Australian, 48), noted self as the key orienting concept in his travels: 'The main focus of my travel is about self.'

Although it was most common for the lifestyle travellers to view travel as a vehicle to engage in an ongoing developmental process of 'learning about the self', some participants approached self in distinctly different ways. First, for a few of these lifestyle travellers, a perception was held that their self-searching was no longer processual, but that they had instead now 'found themselves' in a definitive sense. Second, and in stark opposition to this latter worldview, a few of the lifestyle travellers approached self as a relational concept open to multiple performances across different contexts.

\section{Learning about the self}

The majority of the participants sought to 'learn about the self' and 'get to know the self' as part of a developmental process. Tamara (Canadian/Indian, 34), who had been travelling for the majority of the last 17 years, summed up the assumption of many of the lifestyle travellers that an inner self existed and could be learned about: 'Travelling is really about yourself, about learning what's inside of yourself.' Learning about the self was positioned as 'natural' through travel, regardless of how time was spent while travelling. Fiona (New Zealander, 23), when asked if travel had affected her, had pondered: 'I'd be surprised if you could travel and not learn about yourself.' The lifestyle travellers who believed in travel as a context conducive to learning about one's self hence supported tourism scholarship that cites the construction of self as important to travel experience (Davidson, 2005; Desforges, 2000; Neumann, 1992; Noy, 2004; O’Reilly, 2005, 2006).

Learning about and getting to know the self was communicated as processual and based in daily experience:

Every day you learn about you. Every day you know you more and more. You know who you are more and more. Maybe it's really important to know who you are. For me, it's really important. (Eric, French, 35)

For Eric, who had sold his business in France in order to travel and work casually in Asia indefinitely, learning to be true to his self was an ongoing exercise that he felt required cultivation and practice. Hence, developing knowledge about one's self seemed to function as an ideal for many of the lifestyle travellers. Rather than entertaining the prospect of ultimately 
finding his self, Brendon (Irish, 26) approached his self-searching as a never-ending state of becoming:

You can either work at it and say that I've reached this point, this is where I'm going, I'm here, or you can have it as a kind of ideal, to stay in dynamic movement towards so even if you reach what would be perceived as a really, really high state, you still always have this ideal to push and push so you're within this constant state of becoming, becoming, becoming.

Brendon's perspective, reminiscent of a quest for self-enlightenment, reflected Maslow's (1971: 175) depiction of the ideal of self-actualisation as 'the development of the fullest height that the human species can stand up to or that the particular individual can come to.'

Unsurprisingly, several of the lifestyle travellers felt that the bulk of their selfsearching had taken place in their earlier travels, at times when the individuals would still have been theoretically transitioning into 'adulthood'. This was in contrast to envisioning self-development and gaining self-knowledge as a lifelong journey. Andreas (Swedish, 25) suggested, 'Yeah, I guess you're changing all the time. But I'm guessing the first trip is probably the one where you change the most.' Although issues of self among the interviewees did not seem to be limited by age, it was suggested that chronological age plays a factor in searching for self:

I think when you're younger you tend to be seeking and searching more. Well, it stands to reason. Someone in their twenties, who's looking for who and how they are, you know, they're not quite sure. Someone in their thirties and forties tends to be a bit clearer on that. Maybe in age, one would hope that people are more comfortable in their own skin. They've had longer to live in it. I know I certainly am. (Ryan, Australian, 48)

Developmental views based on chronological age supported Richards and King's (2003) suggestion that more experienced travellers are less likely to be trying to overtly 'find themselves'. Moreover, these lifestyle travellers furthered the representation of one's first extended backpacking trip as a rite-of-passage (O'Reilly, 2006; Riley, 1988), wherein experimentation with temporary roles is institutionally condoned (Cote \& Levine, 2002).

Lev (French/Israeli 30), who claimed that he knew himself in a different way after his travels, felt that learning about one's self is intertwined with being exposed to a variety of cultural contexts through lifestyle travel: 'You know yourself better. You know yourself in different situations from before. So, of course you discover things about yourself because you naturally are in different situations.' Thus, some of the participants viewed 'self-discovery' as more fruitfully undertaken when physically away from their home contexts, as travel reportedly allowed for the experience of new and different situations. Charlotte (Canadian, 26) volunteered this as a nexus between escapism and searching for self: 'It's escapism and it's getting to know yourself. You kind of have to escape your current reality to gain perspective on it, and I think that's why I left Canada to begin with.' Escaping one's current reality reportedly allowed for engagement in 'alternative' realities that offered different ways of perceiving one's self. Marie (French, 26) also commented on the importance of escape in order to have time with one's self: 
When you are away from your homeland, from your family, from the factors that influence your identity, it might be a location to think more in a free way about all these questions of the true self, the true nature.

Some of the participants therefore supported Cohen and Taylor's (1992) assertion that escapism, long posited as a motive for why some individuals go on holiday (Crompton, 1979; Dann, 1977), can be underpinned by a search for one's perceived true self.

A couple of the participants, however, noted that they would have been searching for self even if they had not physically travelled. As Alec (Scottish, 34), a yoga instructor on the island of Koh Tao in Thailand and another traveller of 17 years, stated, when asked if he was looking for anything through his travels:

I think I would have had that whether I would have just stayed in one place all the time. That inner inquiry into the nature of the mind and the spirit; I always had that since I was very young. I think the travelling has maybe amplified it and accelerated certain parts of it. I suppose it [travel] could be a physical representation of the inner search which is going on.

Consequently, it is likely that some of the participants were already primed to search for self prior to their travels. Steph (Australian, 23) supported this notion by having suggested that the need to change an aspect of herself had led her to travel:

When I left Australia I thought I was going because I wanted to be a big explorer and I was going to conquer the world or whatever, but I think it was more to do with I knew I had to change something in my life and I wasn't sure what it was.

The humanist rhetoric of developing and getting to know the inner self was also supported by Charlotte (Canadian, 26), who reinforced the notion that searching for self need not only take place in the context of travel: 'It was a goal to know myself, and travel just kind of went along with it.'

\section{Finding one's self}

In contrast to the many lifestyle travellers who viewed searching for self as an ongoing process, a few of the participants perceived that they had found their self in a final sense. The rarity of using words such as 'finding' or 'found' in regards to self was inconsistent with O'Reilly's (2006: 1004) normative claim that 'backpacking today is often presented in terms of the need to 'find myself'. Nonetheless, Julie (German, 27), seemingly contented with her relatively new life as a dive instructor in Thailand, did make the claim of having ultimately found herself:

I'm not looking for something anymore, I found it. I found myself during the travelling. That's for sure. I know now what I want, what is important for me, what I don't need. I know me better now and I know how I react to situations and I'm much more balanced now. I like myself now.

Julie intended to stay in Thailand indefinitely and believed she would be unable to ever return to the cultural context she came from in Germany, where she had 'felt like a bird in a cage'. 
In another example, Felipe (Cuban, 29), when asked why he was travelling, responded:

I was tired of looking for something, and I was trying just to stop my looking and just finding. In India, I found what I was looking for. I found myself. I feel I have come back. My travels have taken me by hand again to my own home. I was wandering out of my home place, I was just lost. I believe I have never changed since being born, I have just been diverted.

Felipe added credibility to the notion that the concept of 'home' has become increasingly blurred in late modernity as individuals split their attention and presence between multiple places (Hannerz, 2002). Moreover, when Felipe was further questioned as to whether he perceived that he had ultimately found himself, he expanded on what turned out to be his concept of self-enlightenment:

I feel that enlightenment is not like a light that comes to you, it's not like a finish line, it's not like something that you arrive at and everything is perfect. I feel like enlightenment is just the perfect way you can be yourself, and through being yourself, enjoying more.

Hence, while Felipe's view on the search for self clearly rested on the assumption that he has an innate true self that could be discovered, he discounted the possibility of suddenly finding one's self in a final sense.

In any event, most of the participants did not expect to definitively find her/his self. As was neatly stated by Marie (French, 26), when asked if she ever expected to find herself: 'To find myself is a big word, but I'd like to find how I want to live, where I want to live and what I want to do.' Marie's use of travel as a means of trying to address major life decisions challenged Ateljevic and Doorne's (2000) claim that travel is used to avoid important life choices. In Marie's case, travel was instead mobilised to engage directly with negotiating major life options. While several clichés may have been invoked to represent a search for self that many undertook through lifestyle travel, the importance that this search had in giving meaning to the lives of the participants was not to be underestimated.

\section{Performing selves}

In stark contrast to the majority of the lifestyle travellers who viewed self as an object to learn about and develop, and the handful who felt they had found their self in a definitive sense, a few of the participants approached selves as situational or relational, with the potential for multiple performances across different contexts. In a step towards understanding selves as situational, Thomas (English, 29 shared:

Everything's changing constantly, as are you, so the guy who I am today isn't necessarily the guy I am tomorrow, so, I think I've had moments where I felt like I've known myself absolutely, right there and then, but I think I've lost that now actually a little bit.

Thomas suggested that whilst one may feel that the search for self has been momentarily satisfied, such a feeling is inevitably fleeting as selves are bound to change again. 
The maxim of finding one's self through travel was even somewhat lampooned by Laura (Canadian, 28), who seemed to realise for the first time during the interview that she had used travel as a means of addressing issues of self. In contrast to discovering an inner self hidden inside her, Laura described the possibility of choosing to perform whatever selves she wanted:

I think it was when I first went to England, when I was thinking, ok, well, maybe I just need another year off to find myself. I used that term, ha, ha. Maybe I need to leave the country and actually live somewhere else and find myself in a different country where I don't know anyone and I can sort of start fresh and go from there. I don't know anyone so I can be whoever I want, change my personality, which I always sort of figured I'd do but hasn't really happened.

With these latter words, rather than seeking an internal self, Laura seemed to have embraced the idea of changing her environment so that she could be whomever she wanted. Laura evoked a concept of self that has the potential for multiple selves or performances (Edensor, 2001), reflecting Goffman's (1959) notion that different roles can be played for different people and lending capital to poststructural claims that a permeable self might pave the way for increasing possibilities (Gergen, 1991).

In a similar vein, when asked what 'grabbed him' when he first started travelling, Barry (English, 32) related: 'I suppose it is that, kind of, you can just shed a life each time you change places. You can just change your life each time you want to go somewhere new.' For Laura and Barry, self was not necessarily an essentialist object to be developed, but instead situational and open to various performances (Bell, 2008; Butler, 1990). In contrast to the majority of the other lifestyle travellers, these latter views were more representative of the trend in the social sciences to conceive selves as relational, multiple, performed and contextually dependent (Bell, 2008; Finnegan, 1997; Vaughan \& Hogg, 2002). As Laura stressfully reported, however, her hope to change into 'whomever she wanted' had not transpired. Furthermore, Barry went on to describe how his travels were still nonetheless marked by an element of searching:

I'm always going to be searching because I do think I'm missing something and I don't know what it is and I'll know when I find it. I will keep travelling as long as it makes me happy and as long as I think there's something out there.

\section{CONCLUSION}

This paper has sought to problematise the concept of searching for self in the context of lifestyle travellers. Opposing theoretical perspectives on self were reviewed, which included first tracing the historical status of an essentialist self so as to highlight the notion of a 'true inner self' as socially constructed and culturally contingent. In contrast to this monological view of self that fails to recognise the role of discourse in co-constructing selves, self was then conceptualised as dialogical, based on understandings of selves as relational and situationally mediated. In this latter sense, selves are not innate fixed givens, but are instead in flux as they are socially constituted through embodied performances as an ongoing process of becoming. Even though the social sciences may have largely moved on to consider the 
constitution of selves in a relational and performed light wherein individuals offer different narratives across different situations, many individuals nonetheless attempt to reflexively construct a coherent sense of self that reflects unity and purpose (Giddens, 1991; McAdams, 1997). Such was the case with the majority of the lifestyle travellers in the current research, for whom the search for a unified sense of self, in stark opposition to a relational view on self, was an important motivating factor for their travels.

The narrations of the lifestyle travellers contained divergent perspectives on how the search for self was conceived and approached. Searching for self was most often characterised by a developmental vocabulary, mobilised through phrases such as 'learning about the self' and 'getting to know the self'. In some cases, self was seen as discoverable or discovered, in the definitive sense of 'finding one's self'. In significant contrast to these participants, a few of the lifestyle travellers alluded to selves as relational and open to multiple performances. A common thread among the majority of the participants, however, was an understanding of self predicated on an essentialist reading of it as an innate inner object. Thus, many of the participants had been or were still on a Romantic modern quest of searching for their "true self'. However, the opposing and now widely accepted sociological view that selves are relational and situational disqualifies the notion of experiencing a true inner self (Danziger, 1997; Finnegan, 1997). Without a true inner self to actualise, realise, transform, find and/or develop, many of the lifestyle travellers can be seen as chasing a mirage. The paradox of questing for an inner self, which in itself is a historically constructed myth, indicates that many of the lifestyle travellers were engaged in an ongoing performance of the modern metanarrative of self as a developmental project.

Despite a critical view of the inner self as a social construction, Elsrud's (2001: 599) words on the importance of emic perspectives have resonance: 'Statements from interviews will demonstrate that no matter how much academic knowledge is extracted from their testimonies, their experiences are as valid and real to them as the construction is to the researcher.' Lefcourt (1973: 417) further highlights the importance of personal perceptions in noting that even 'illusions do have consequences.' Although the pursuit of one's true self may be fruitless in an 'objective' sense, the search for self still held meaning and importance for many of the participants. Thus, rather than representing Urry's (2002) 'post-tourist', for whom tourism is mainly play and progress is not necessary, the majority of the lifestyle travellers here portrayed a serious quest for meaning through their travels. Whilst these lifestyle travellers may have romantically valued travel as a vehicle in searching for their true selves, future tourism scholarship that may be tempted to continue to paint promises of selfactualisation, self-realisation, self-fulfillment, discovering one's self and self-development through tourism, may be well advised to take a cautious approach to these ideals that have been constructed upon the shaky foundations of an essentialist self.

\section{Acknowledgements}

I wish to thank Associate Professor Neil Carr and Professor James Higham for their helpful feedback. Furthermore, I would like to acknowledge funding from the University of Otago (New Zealand) Postgraduate Publishing Bursary (PhD). 


\section{REFERENCES}

Appiah, K.A. (1994). Identity, authenticity, survival: Multicultural societies and social reproduction. In A. Gutmann (Ed.), Multiculturalism: Examining the Politics of Recognition (pp. 149-163). Princeton: University.

Ashmore, R.D. \& Jussim, L. (1997). Toward a second century of the scientific analysis of self and identity. In R.D. Ashmore \& L. Jussim (Eds.), Self and identity: Fundamental issues (pp. 3-19). New York: Oxford University.

Ateljevic, I. \& Doorne, S. (2000). Tourism as an escape: Long-term travellers in New Zealand. Tourism Analysis, 5(2), 131-136.

Baumeister, R.F. (1986). Identity: Cultural change and the struggle for self. New York: Oxford University.

Baumeister, R.F. (1991). Escaping the self: Alcoholism, spirituality, masochism, and other flights from the burden of selfhood. USA: BasicBooks.

Beedie, P. (2007). Legislators and interpreters: An examination of changes in philosophical interpretations of 'being a mountaineer'. In M. McNamee (Ed.), Philosophy, risk and adventure sports (pp. 25-42). New York: Routledge.

Bell, E. (2008). Theories of performance. Los Angeles: Sage.

Breathnach, T. (2006). Looking for the real me: Locating the self in heritage tourism. Journal of Heritage Tourism, 1(2), 100-120.

Burkitt, I. (1991). Social selves: Theories of the social formation of personality. London: Sage.

Butler, J. (1990). Performative acts and gender constitution: An essay in phenomenology and feminist theory. In S. Case (Ed.), Performing feminisms: Feminist critical theory and theatre (pp. 270-282). Baltimore: Johns Hopkins University.

Cohen, E. (1979). A phenomenology of tourist experiences. Sociology, 13(2), 179-201.

Cohen, E. (1996). The sociology of tourism: Approaches, issues, and findings. In Y. Apostolopoulos, S. Leivadi, \& A. Yiannakis (Eds.), The sociology of tourism: Theoretical and empirical investigations (pp. 51-71). London: Routledge.

Cohen, E. (2004). Backpacking: Diversity and change. In G. Richards \& J. Wilson (Eds.), The global nomad: Backpacker travel in theory and practice (pp. 43-59). Clevedon: Channel View.

Cohen, S.A. (2010a). Re-conceptualising lifestyle travellers: Contemporary 'drifters'. In K. Hannam \& A. Diekmann (Eds.), Beyond backpacker tourism: Mobilities and experiences (pp. 64-84). Clevedon: Channel View.

Cohen, S.A. (2010b). Personal identity (de)formation among lifestyle travellers: A doubleedged sword. Leisure Studies, 29(3), 289-301. 
Cohen, S.A. (2011) 'Lifestyle travellers: Backpacking as a way of life', Annals of Tourism Research, doi: 10.1016/j.annals.2011.02.002.

Cohen, S. \& Taylor, L. (1992). Escape attempts: The theory and practice of resistance to everyday life. London: Routledge.

Collinson, J.A. \& Hockey, J. (2007). 'Working out' identity: Distance runners and the management of disrupted identity. Leisure Studies, 26(4), 381-398.

Cote, J.E. \& Levine, C.G. (2002). Identity formation, agency, and culture: A social psychological synthesis. Mahwah: Lawrence Erlbaum Associates.

Crompton, J. (1979). Motivations for pleasure vacation. Annals of Tourism Research, 6(4), 408-424.

Dann, G. (1977). Anomie, ego-enhancement and tourism. Annals of Tourism Research, 4(4), 184-194.

Danziger, K. (1997). The historical formation of selves. In R.D. Ashmore \& L. Jussim (Eds.), Self and identity: Fundamental issues (pp. 137-159). New York: Oxford University.

Davidson, K. (2005). Alternative India: Transgressive spaces. In A. Jaworski \& A. Pritchard (Eds.), Discourse, communication and tourism (pp. 28-52). Clevedon: Channel View.

Desforges, L. (2000). Traveling the world: Identity and travel biography. Annals of Tourism Research, 27(4), 926-945.

Edensor, T. (2001). Performing tourism, staging tourism. Tourist Studies, 1(1), 59-81.

Elsrud, T. (2001). Risk creation in traveling: Backpacker adventure narration. Annals of Tourism Research, 28(3), 597-617.

Finnegan, R. (1997). 'Storying the self': Personal narratives and identity. In H. Mackay (Ed.), Consumption and everyday life (pp.66-111). London: Sage.

Foucault, M. (1988). Technologies of the self. In L. Martin, H. Gutman \& P. Hutton (Eds.), Technologies of the self: A seminar with Michel Foucault (pp.16-49). London: Tavistock

Gergen, K.J. (1991). The saturated self: Dilemmas of identity in contemporary life. USA: BasicBooks.

Giddens, A. (1991). Modernity and self-identity: Self and society in the late modern age. Cambridge: Polity.

Goeldner, C.R. \& Ritchie, J.R.B. (2006). Tourism: principles, practices, philosophies, $10^{\text {th }}$ edition. Hoboken: John Wiley \& Sons.

Goffman, E. (1959). The presentation of self in everyday life. Middlesex: Penguin Books.

Hall, S. (1996). Introduction: Who needs 'identity’. In S. Hall \& P. du Gay (Eds.), Questions of cultural identity (pp. 1-17). London: Sage. 
Hannerz, U. (2002). Where we are and who we want to be. In U. Hedetoft \& M. Hjort (Eds.), The postnational self: Belonging and identity (pp. 217-232). Minneapolis: University of Minnesota.

Harter, S. (1997). The personal self in social context: Barriers to authenticity. In R.D. Ashmore \& L. Jussim (Eds.), Self and identity: Fundamental issues (pp. 81-105). New York: Oxford University.

Holland, D. (1997). Selves as cultured: As told by an anthropologist who lacks a soul. In R.D. Ashmore \& L. Jussim (Eds.), Self and identity: Fundamental issues (pp. 160-190). New York: Oxford University.

Hughes, G. (1993). The self, signification and the superyacht. Leisure Studies, 12(4), 253265.

Jenkins, R. (1996). Social identity. London: Routledge.

Kuentzel, W.F. (2000). Self-identity, modernity, and the rational actor in leisure research. Journal of Leisure Research, 32(1), 87-92.

Leed, E.J. (1991). The mind of the traveller: From Gilgamesh to global tourism. USA: BasicBooks.

Lefcourt, H.M. (1973). The function of the illusions of control and freedom. American Psychologist, 28(5), 417-425.

McAdams, D.P. (1997). The case for unity in the (post)modern self: A modest proposal. In R.D. Ashmore \& L. Jussim (Eds.), Self and identity: Fundamental issues (pp. 46-78). New York: Oxford University.

Maoz, D. (2007). Backpackers' motivations: The role of culture and nationality. Annals of Tourism Research, 34(1), 122-140.

Maslow, A. (1970). Motivation and personality, $2^{\text {nd }}$ edition. New York: Harper \& Row.

Maslow, A. (1971). The farther reaches of human nature. Middlesex: Penguin Books.

Miles, M.B. \& Huberman, A.M. (1994). Qualitative data analysis: An expanded sourcebook. Thousand Oaks: Sage.

Neumann, M. (1992). The trail through experience: Finding self in the recollection of travel. In C. Ellis \& M.G. Flaherty (Eds.), Investigating subjectivity: Research on lived experience (pp. 176-201). Newbury Park: Sage.

Noy, C. (2004). This trip really changed me: Backpackers' narratives of self-change. Annals of Tourism Research, 31(1), 78-102.

Noy, C. \& Cohen, E. (2005). Introduction: Backpacking as a rite of passage in Israel. In C. Noy \& E. Cohen (Eds.), Israel backpackers and their society: A view from afar (pp.1-43). Albany: State University of New York.

O'Reilly, C.C. (2005). Tourist or traveller? Narrating backpacker identity. In A. Jaworski \& A. Pritchard (Eds.), Discourse, communication and tourism (pp. 150-169). Clevedon: Channel View. 
O'Reilly, C.C. (2006). From drifter to gap year tourist: Mainstreaming backpacker travel. Annals of Tourism Research, 33(4), 998-1017.

Patton, M.Q. (2002). Qualitative research and evaluation methods. Thousand Oaks: Sage.

Richards, G. \& King, B. (2003). Youth travel and backpacking. Travel and Tourism Analyst, $6,1-23$.

Richards, G. \& Wilson, J. (2003). Today's youth travellers: Tomorrow's global nomads. New horizons in independent youth travel and student travel, A report for the International Student Travel Confederation (ISTC) and the Association of Tourism and Leisure Education (ATLAS). Amsterdam: ISTC.

Riley, P.J. (1988). Road culture of international long-term budget travellers. Annals of Tourism Research, 15(3), 313-328.

Rogers, C.R. (1969). Freedom to learn. Columbus: Charles E. Merrill.

Rojek, C. (1993). Ways of escape: Modern transformations in leisure and travel. Houndmills: MacMillan Press.

Seigel, J. (2005). The idea of the self: Thought and experience in Western Europe since the seventeenth century. Cambridge: Cambridge University.

Simmel, G. (1971). On individuality and social forms. London: University of Chicago.

Sørensen, A. (2003). Backpacker ethnography. Annals of Tourism Research, 30(4), 847-867.

Uriely, N., Yonay, Y., \& Simchai, D. (2002). Backpacking experiences: A type and form analysis. Annals of Tourism Research, 29(2), 520-538.

Urry, J. (2002). The tourist gaze, $2^{\text {nd }}$ edition. London: Sage.

Vaughan, G.M. \& Hogg, M.A. (2002). Introduction to social psychology, $3^{\text {rd }}$ edition. Frenches Forest: Pearson Education.

Veal, A.J. (2006). Research methods for leisure and tourism: A practical guide, $3^{\text {rd }}$ edition. Harlow: Pearson Education.

Walseth, K. (2006). Young Muslim women and sport: The impact of identity work. Leisure Studies, 25(1), 75-94.

Ward, C., Bochner, S., \& Furnham, A. (2001). The psychology of culture shock, $2^{\text {nd }}$ edition, East Sussex: Routledge.

Wearing, S. \& Wearing B. (2001). Conceptualizing the selves of tourism. Leisure Studies, 20, 143-159.

Welk, P. (2004). The beaten track: Anti-tourism as an element of backpacker identity construction. In G. Richards \& J. Wilson (Eds.), The global nomad: Backpacker travel in theory and practice (pp. 77-91). Clevedon: Channel View.

Westerhausen, K. (2002). Beyond the beach: An ethnography of modern travellers in Asia. Bangkok: White Lotus. 